\title{
The Response Relationship between Land Use/Land Cover and Watershed Lagged Effect based on Different Time Scales-A Case Study in Central Guizhou of China*
}

\author{
Zhonghua he ( $\nabla$ hezhonghua7621@126.com ) \\ Guizhou Normal University \\ Cuiwei Zhao \\ Guizhou Normal University \\ Hong Liang \\ Guizhou Normal University \\ Zhaohui Yang \\ Guizhou Province
}

\section{Research Article}

Keywords: Lagged effect, Watershed water storage, Human activities, Karst drainage basin.

Posted Date: June 29th, 2021

DOl: https://doi.org/10.21203/rs.3.rs-564002/v1

License: (c) (1) This work is licensed under a Creative Commons Attribution 4.0 International License.

Read Full License 


\title{
The response relationship between land use/land cover and watershed lagged effect based on different time scales--a case study in Central Guizhou of China*
}

\author{
Zhonghua He ${ }^{1,2^{*}}$,Cuiwei Zhao ${ }^{1}$,Hong Liang ${ }^{1}$, Zhaohui Yang ${ }^{3}$
}

\author{
(1. School of Geographic and Environment Science, Guizhou Normal University, Guiyang, Guizhou, 550001, China \\ 2.School of Geography and Environment Sciances, Guizhou Normal University / State Engineering Technology Institute for Karst \\ 3. Department of Emergency Management of Guizhou Province, Guiyang, Guizhou, 550001, China)
}

Abstract: As we all know, the drought occurrence indicates that there is no rainfall or little rainfall in a certain period. However, the no or little rainfall does not mean that the droughts must be occur, and the occurrence of droughts shows a certain lag in the different areas. This paper analyzes the characteristics of watershed lagged effects and human activities in Central Guizhou of China (CGC) by the Lagged Index $(L I)$ and Landscape Index $(L I)$ based on the land use data, rainfall and runoff data during the periods of 1971-2016.The results show that (1) the influence difference of the same land use type on the lagged intensity was particularly significant $(P<0.001)$ in the different ages $(1970 \mathrm{~s}-2010 \mathrm{~s})$. Among them, it gradually increased for the impacts of the wood land, grass land and cultivated land on the lagged intensity with the increasing of ages, and reached the maximum in the 2000s, and reached the maximum in the 2000s, while it did not change significantly for the water land and construction land.๑ The impact of land use type transfer on watershed lagged effects is particularly significant $(P<0.001)$.Among them, it gradually increases for the wood land transfer with the prolongation of lagged periods, and reaches the maximum for the construction land transfer in the lag-1 period $\left(X_{t-1}\right)$, and is not significant for the rest type transfer.3 The impact differences of the principal components (Zs) on watershed lagged effects are particularly significant for the morphological characteristics of land use types in different lagged periods $\left(X_{t-0}-X_{t-3}\right)$, and different ages (1970s-2010s), as well as the different time scales (1-12 months). Among them, it is the largest for the impact of grass land and water land on watershed lagged intensity, and gradually increases with the increasing of time scales (the maximum in the 9-month scale), followed by the wood land and cultivated land with the maximum in the 9- and 6- month scales, respectively. And it is the smallest for the construction land, and gradually increases with the increasing of time scales (the maximum in the 9-month scale).

\footnotetext{
* Corresponding author.

Email:hezhonghua7621@126.com (Z. He).
} 


\section{Introduction}

As we all know, the drought occurrence indicates that there is no rainfall or very little rainfall in a certain period,

while it does not mean that the drought must be occur without rainfall or little rainfall in some periods. There is a certain lag for the occurrence of droughts in different regions, and its lag time and intensity are greatly affected by watershed water-stored capacity. Therefore, the drought is more influence by the watershed water storage (soil, aquifer, lake, river) whether than by the rainfall deficit. It means that drought may occur in high flow seasons (van Loon, 2013). Hence the study on driving mechanism of watershed lagged effects will contribute to the monitoring and prediction of Karst drought.

There are the double aquifer media and double water system structures on the surface and underground in Karst drainage basins where it has the sieve and threshold effects on the atmospheric precipitation, which will affect the watershed runoff recharge, and show the special hydrological effects. For example, compared with the non-Kart basins, the peak runoff modulus, low flow modulus and Coefficient of Variation $\left(C_{v}\right)$ in Karst basins tend to a similar and stable value with the increasing of basin spatial scales (Liang et al., 1995 \& 1997). The different spatial scales of Karst basins and different spatial coupling of landform types will have great differences on the impact of flood peak effects. The studies show that it is represented the positive proportional relationship between the flood peak and basin area in the non-Kart basins, and a special relationship in the medium and small Karst basins (Liang, et al., 1998). In the Karst areas, lithology is an important component of basin underlying media, and its lithologic type and structure will control the development of the landform and water system, promote the formation of watershed water-stored spaces and affect the watershed water-stored capacity (he et al., 2015). For example, the higher the limestone proportion is, the smaller the low flow modulus is, and the higher the dolomite proportion is, the larger the low flow modulus is. The higher the 
proportion of peak-cluster depression is, the smaller the low flow modulus is, and the larger the proportion of Feng Lin plain (basin) is, the higher the low flow modulus is (Wang et al., 2002). In terms of the relationship between the structure and function of soil systems, He et al., (2013a \& 2013b) analyzed the influences of a single factor, multi-factor coupling of soil single factor, as well as the soil multi-factor coupling on the watershed water-stored capacity, and revealed the driving mechanism of watershed water-stored capacity to hydrological droughts. They found that the order of the influences of soil four factors on hydrological droughts is Soil Relative Roughness $(R=0.968)>$ Soil Relative Coverage $(R=0.56)>$ Soil Relative Humidity $(R=0.558)>$ Soil Type $(R=0.464)$. Similarly, hydrology drought is more influenced by the patch density and maximum patch distributions of land use types than by the patch edge and shape distributions. The larger the patch fractal dimension index of land types, the smaller the impact of land use type distributions on hydrological droughts (He et al., 2014).

In summary, there are many types of media (lithology, soil, vegetation and land use, etc.), impure texture and complex structure in Karst drainage basin. Such as different sizes of dissolution gaps and holes and pipes, formed under the differential erosion or dissolution effects of soluble water, will provide the spaces and places for the atmospheric precipitation lagged flow on the surface and underground. And it results in the basins having a certain water-stored capacity (He et al., 2013a, 2013b ,2014 \& 2015), as well as the different hydrological responses to climate changes in the different time scales (López-Moreno et al.,2013). For instance, to explore the propagation process from the meteorological to hydrological drought, Li et al., (2020a) quantified the meteorological drought, hydrological drought, agricultural drought and vegetation drought by the drought indices, such as the Standardized Precipitation Index (SPI), Standardized Runoff Index (SRI), Standardized Streamflow Index (SSI) and Vegetation Health Index (VHI).It is found that the propagation time is within one month from meteorological to hydrological drought, within two months from hydrological to soil moisture, and between two to three months from hydrological to vegetation drought. The lag response time of agricultural drought to meteorological drought and hydrological drought to agricultural drought has obvious seasonal characteristics with the spring and winter longer, autumn and summer shorter (Li et al., 2020b). 
Meanwhile, the lagged effect of hydrological drought on meteorological drought has particularly significant differences in the different basins, and the climate and land use/land cover are the main factors affecting the propagation process from the meteorological to hydrological drought (Zhao et al., 2019;Zhou et al., 2019) . The response of vegetation to rainfall varies with the changing of soil types. It is found that there is a linear relationship between the NDVI and rainfall when the rainfall is lower than the saturation threshold. However, the NDVI value increases slightly only with additional rainfall when the rainfall exceeds the threshold (Nicholson et al.,1994; Niu et al., (2018).

Therefore, this paper will firstly judge the lagged response of runoff to rainfall by the distribution-lagged regression model in Central Guizhou of China (CGC), and calculate the Lagging Index ( $L I$ ) based on the meteorological and hydrological data during the periods 1971-2016. Secondly, to simulate the human activities of the 1970s, 1980s, 1990s, 2000s and 2010s based on land use/land cover data of the 1975, 1985, 1995, 2005 and 2015, respectively. To analyze the spatial-temporal evolution characteristics of human activities in the CGC. Finally, it is discussed for the driving mechanism of human activities on watershed lagged effect. Therefore, the research of this paper will establish a theoretical basis for the monitoring and prediction of droughts in Karst drainage basins.

\section{Study areas}

Qianzhong Regions are located in Central Guizhou of China (CGC) enclosed by the eastern longitudes of $104^{\circ} 19^{\prime} 10^{\prime \prime} \sim 107^{\circ} 1^{\prime} 11^{\prime \prime}$ and northern latitudes of $25^{\circ} 24^{\prime} 30^{\prime \prime} \sim 26^{\circ} 52^{\prime} 30^{\prime \prime}$ with an area of $1,6563.5 \mathrm{Km}^{2}$ and an average elevation of $1367.02 \mathrm{~m}$ (Fig. 1). The climate belongs to the subtropical monsoon humid climate area with the annual average precipitation $850 \sim 1510 \mathrm{~mm}$. A high value areas of rainfalls are formed in the Puding, Zhenning, Anshun to Zhijin. The rainfall volumes are decreasing from the middle to the northwest and eastward in Qianzhong Regions, with the largest $(1508.2 \mathrm{~mm})$ in the Liuzhi Station and the smallest $(854.2 \mathrm{~mm})$ in the west of the Hezhang Station. The annual precipitation varies little with the uneven distribution within a year, and the precipitation is concentrated in summer, accounting for about $80 \%$ of the annual precipitation. The study area is located in the wide and gentle slope 
Ridge of Yangtze River and Pearl River Basins. The north of the ridge line belongs to the Wujiang River System in the

Yangtze River Basin. It mainly includes the main stream of Sancha River and its tributaries, Baiyan River, Laolongqiao

River, Boyu River, Chengguan River, Maotiao River and Nanming River, etc. The south of the ridge line belongs to the

Beipanjiang and Hongshui river water systems in the Pearl River Basin. It mainly includes the Wanger River and Baling

River of Beipan River tributaries, and the Maoying River and Getu River of the Hongshui River tributaries, etc.
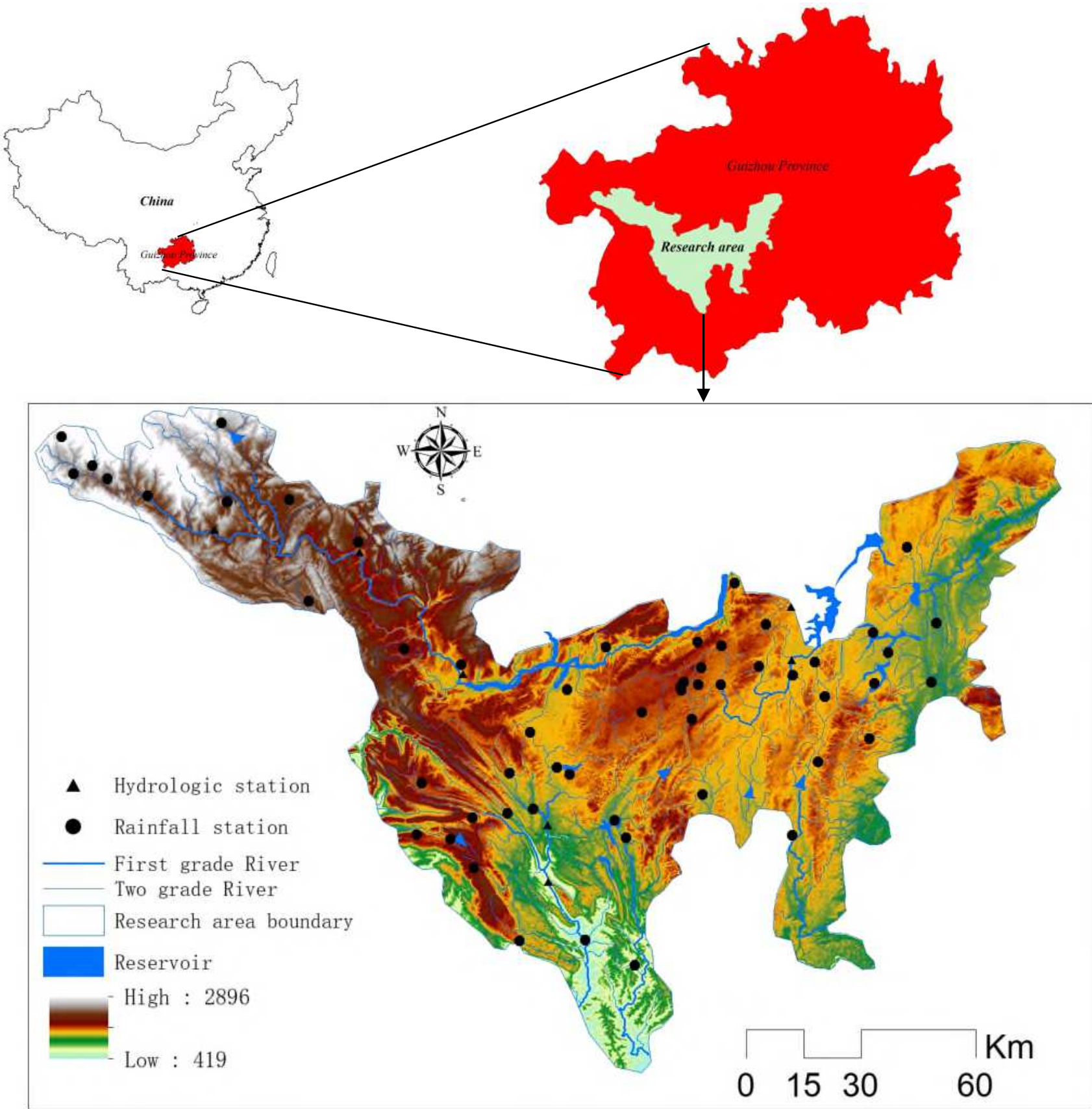

Fig. 1 Distribution Diagram of Research Areas

\section{Data and Methods}


The land use/land cover changes were represented by the land use data of 1975, 1985, 1995, 2005 and 2015 in this

paper, which was mainly come from the resource and environmental science and data center (http://www.resdc.cn)

(Resource and Environment Science and Data Center, China) (Fig.2). The land use types was divided referring to the primary and secondary classification standards in this paper.

\subsection{Rainfall and hydrological data} and hydrological data were standardized in this paper.

\subsection{Lagging index}

The distribution-lagged regression model was calculated as follows:

$$
\mathrm{y}_{t}=\alpha+\sum_{i=0}^{k} \beta_{t-i} X_{t-i}+\mu_{t}
$$

138 the $\mathrm{t}$-th time rainfall. It means that the smaller the value of $\beta_{t-i} x_{t-i}$, the smaller the lagged-flow volume, and the

(1) Hydrologic Year Book of People's Republic of China Hydrologic Data of Yangtzi River Basin, Volume 6 and Hydrologic Data of Pearl River Basin, Volume 8. 

stronger the lagged effect. Or the contribution rate of the i-th lagged variable $\left(X_{t-i}\right)$ to the current period variable $\left(\mathrm{y}_{t}\right)$ is small. $\mu_{t}$ represents a random variable at the time t. $\alpha$ is a constant, $\mathrm{k}$ represents a length of lagged periods, $\mathrm{m}$ is a polynomial order, and $\mathrm{d}$ is a controlling parameter of lagged characteristics, respectively. Among them, $\mathrm{k}=3$, $\mathrm{m}=2$, and $\mathrm{d}$ is the defect value in this paper.

Finally, to calculate the Lagging Index $(L I)$ that can be expressed as follows:

$$
L I_{\mathrm{i}, s}=\frac{V_{i, s}-\overline{V_{\mathrm{i}}}}{S_{i}}, i=0,1,2,3, \mathrm{~s}=1,2, \Lambda, 6
$$

Where $V_{i, s}=\beta_{t-i} X_{t-i}$ represents the lagged-flow volume at the s-th reference period, i-th lagged period. $\overline{V_{i}}, \mathrm{~S}_{\mathrm{i}}$ represent the mean value and standard deviation of lagged-flow volume at the i-th lagged period, respectively. In this paper, $\mathrm{i}=0$ represents the lag- 0 period (i.e., current month), $\mathrm{i}=1$ represents the lag- 1 period $(\operatorname{lag}$ month 1$), \ldots \mathrm{i}=3$ represents the lag-3 period (lag months 3 ), and $s=1$ represents the $1960 \mathrm{~s}, \mathrm{~s}=2$ represents the $1970 \mathrm{~s}, \ldots$, $s=6$ represents the 2010s, respectively.

$L I$ is positive, indicating normal (i.e., no lagged effect). $L I$ is negative, and the larger the absolute value, the more serious the lagged intensity (He et al.,2018a \& 2018b).

\section{Results and analysis}

\subsection{Spatial distribution pattern and evolution characteristics of land use/land cover}

\subsubsection{Analysis of land use type characteristics}

(1) In general, the land use types in Central Guizhou of China (CGC) were mainly shown the wood land (41.2\%), cultivated land $(30.4 \%)$, grass land $(26.6 \%)$, construction land $(1.37 \%)$, water land $(0.355)$ and unused land $(0.02 \%)$ in the 1970s-2010s (Fig. 2). It means that there was great difference of human activity intensities in the 1970s-2010s. (2) The spatial distribution differences of different land use types are larger $\left(C_{v}=1.1\right)$ within a year (age). Among them, the wood land and cultivated land are mainly distributed in the Central, Eastern and Southern of research areas with the 
Liupanshui, and the water land is scattered distributed in the central part with Puding as the center. Indicating that the

162 interconversion rate between different land use types is larger within the same period (age), namely, human activities

163

164

165

166

167

168

169

170

171

172

173

174

175

176

177

178

179

180

181

182

183

are stronger. (3) The spatial distribution difference of the same land use type is smaller $\left(C_{v}=0.1\right)$ between different

periods (ages). Among them, there are no differences $\left(C_{v}=0.0\right)$ for the spatial distributions of wood land, grass land and unused land. Indicating that the interconversion rate of same land use type is smaller between different periods (ages),

namely, the differences of human activity intensities are not significant.

\subsubsection{Evolution analysis on spatial pattern of land use/land cover}

(1) In general, the overall changing rate of land use/land cover in the CGC was shown an upward trend in the 1970s-2010s. Among them, the changing rate of land use types was $1.26 \%$ in the $2000 \mathrm{~s}-2010 \mathrm{~s}, 0.53 \%$ in the 1990s-2000s, $0.01 \%$ in the 1980s-1990s, respectively. By comparison, the overall changing rate of land use types in the CGC was the largest in the 2000s-2010s, the smallest in the 1980s-1990s. Meaning that the land use/land cover changes were relatively rapid and human activities more intense in the 2000s-2010s, and relatively slow and human activities relatively gentle in the 1980s-1990s (Fig. 3a). (2) The annual variation rate of the same land use type was larger between different periods (ages), and showed a positive-negative difference (Figs.3 b-e). Among them, the negative change was found in cultivated land and grass land in the 1970s-1980s, positive change in the rest types; and there was negative maximum (-45.74\%) for the cultivated land changes, and positive maximum (10\%) for the unused land changes (Fig. 3b). There was negative change observed in the cultivated land (-32.1\%) and grass land (-40.96\%) in the 1980s-1990s, positive change in the wood land (8.86\%), and no change in the rest types (0\%) (Fig. 3c). A negative change (-49.89\%) for the wood land in the 1990s-2000s, and a positive or no change for other types (Fig. 3d).The negative change was presented in the cultivated land, grass land and unused land, and positive change in the rest types. It is the negative maximum (-13.83\%) in the grass land and positive maximum (10\%) in the water land (Fig. 3e). (3) In summary, a decreasing trend was found in the cultivated land and grass land areas in the 1970s-2010s, an increasing trend in the water land and construction land areas, and the increasing and decreasing trends in the woodland and 
unused land areas. Among them, there was the fastest declining rate of areas for the cultivated land (-45.74\%) in the 1970s-1980s, the wood land $(-49.89 \%)$ in the 1990s-2000s, and the grass land $(-40.96 \%)$ in the 1980s-1990s, respectively. And there was the fastest increasing rate of areas for the wood land (10\%) and construction land (9.62\%) in the 2000s-2010s. However, the unused land area was decreased from the positive maximum (10\%) in the 1970s-1980s to the negative maximum (-1.85\%) in the 2000s-2010s.

\subsubsection{Morphological characteristics analysis of land use types}

The morphological characteristic of land use types is an important parameter reflecting land use/land cover, and an important index reflecting human activities. The 48 indicators of morphological characteristics, such as the Largest Patch Index (LPI) (Range: $0<L P I \leq 100)$, Edge Density $(E D) \quad$ (Range: $E D \geq 0$ ), as well as the Shape index (SHAPE) (Range: $S H A P E \leq 1)$ and Fractal dimension index (FRAC) (Range:1 $\leq F R A C \leq 2$ ), were extracted based on the land use data of 1975, 1985, 1995, 2005 and 2015 by the Software Package of Fragstats 4.0 in this paper(Fig.4). And for the LPI, $E D, S H A P E$ and FRAC were analyzed as follows.

(1) In general, the LPIs have more differences between different land use types. Among them, the largest LPI is the grass land (4.0-7.0), followed by the wood land (4.0-5.0) and cultivated land (4.0-4.5), and the smallest (0.1) the water land. It demonstrates that the relatively concentrated and continuous the grassland distribution is, and the relatively scattered and broken the water land distribution. There was more difference for the LPI of grass land, an increasing trend with the increase of years (ages) in the 1970s-2010s, followed by the wood land and cultivated land, and no difference for the unused land, construction land and water land. It indicates that there is larger impact of human activites on wood land and cultivated land than on grass land in the 1970s-2010s, not significant impact on the unused land, construction land and water land (Fig.4a). (2) The Fig.4 shows that the most complex the patch boundary condition of cultivated land is, followed by the wood land and grass land, and the relatively single the unused land, construction land and water land. Meanwhile, the patch boundary conditions of six types of land use/land cover varied little with the increasing of years (ages) in the 1970s-2010s. (3) The SHAPE of six types of land use/land cover is less 
than 1 , which indicates that the relatively complex the patch shape distributions of six types of land use/land cover are.

Among them, there is relatively smaller $(<0.3)$ for the SHAPEs of the wood land, grass land and cultivated land, and

relatively larger $(<0.6)$ for the he unused land, construction land and water land. Meanwhile, the SHAPEs of six types of

land use/land cover changed less with the increasing of years (ages) in the 1970s-2010s, which indicates that there is

smaller impact of human activities on shapes of land use types in different years (ages) (Fig.4c). (4) Similarly, the

FRACs of six types of land use/land cover are greater than 1, and remain basically unchanged with the increasing of

differences between the different years (ages), which shows that there is smaller impact of human activities on shapes of land use types (Fig.4d).

\subsection{Response relationship between the land use/land cover and watershed lagged effect}

\subsubsection{Response relationship between land use type and watershed lagged effect}

(1) In general, the land use/land cover all have some impacts on the watershed lagged effects, and different types

of land uses show a positive and negative differences. Among them, the positive effect on the lagged intensity is found in the wood land and water land, the negative effect in other types, and the effect on the lagged frequency is just the opposite (Figs.5,6). (2) The impact difference of the same type of land use/land cover on watershed lagged effect is larger in different time scales (1-12 months). Among them, the largest impact difference on lagged intensity is found in land and construction land, and the smallest in the water land and unused land increased with the increase of time scales

(Fig.5). The largest impact difference on lagged frequency is observed in the wood land, and it is declined with the 
intensity/frequency are particularly significant $(P<0.001)$ in the same time scale by the variance analysis. Especially the

$230 F$ value of the impacts on lagged intensity is the largest (199.735) in the 3-month scale, and that of the impacts on

231 lagged frequency is gradually decreasing with the increase of time scales. Meanwhile, the coupling impacts between

232 land use types and time scales (1-12 months) on the watershed lagged frequency are particularly significant $(P=0.02)$,

233 but the impacts on the watershed lagged intensity do not pass the significance test $(P>0.05)$. (3) Except for the unused

234 land, the impact difference of the same type of land use/land cover on watershed lagged intensity was particularly

significant $(P<0.001)$ in the 1970s-2010s. Among them, the impact difference was gradually increasing for the wood

land, grass land and cultivated land with the increase of time scales, and reached the maximum for the cultivated land in

the 2000s.However, the impact difference was smaller for the water land and construction land with the change of ages

(Fig. 5). It was very significant $(P<0.001)$ for the influence difference of the wood land, grass land and unused land in

the 1970s-2010s, and very small ( $P>0.05)$ for the cultivated land, water land and construction land (Fig. 6). The impact

difference of different types of land use/land cover on watershed lagged effect was particularly significant $(P<0.001)$

in the same age. Especially the impact of different types of land use/land cover on lagged intensity was gradually 


\subsubsection{Response relationship between land use type transfer and watershed lagged effect}

(1) The impacts of the land use type transfer on the watershed lagged effects is very significant $(P<0.001)$ with a positive and negative difference shown as the Fig.7. Among them, the positive impact of land use type transfer on the watershed lagged intensity was observed in the wood land (1970s-1990s \& 2000s-2010s) and water land (1980s-2000s), the negative impact in the rest types. And the positive impact of land use type transfer on the watershed lagged frequency was found in the cultivated land (1970s-1980s \& 1990s-2000s), grassland (1980s-2000s) and construction land regions, the negative impact in other types. (2) The impact difference of land use type transfer on the watershed lagged effect was particularly significant $(P<0.001)$ with the changing of ages $(1970 \mathrm{~s}-2010 \mathrm{~s})$. Among them, the $R$ absolute value of impacts between the wood land and grass land on lagged intensity was shown the same changing direction, namely, a increase-decrease-increase trend, and just the opposite in the cultivated land, presented a decrease-increase-decrease trend. There was an inverted V-shape in the water land reached the maximum in the 1990s-2000s, and the smaller in the construction land and unused land. And the $R$ absolute value of the impacts on the lagged frequency was appeared an increase-decrease-increase trend in the wood land and grass land, and a decrease-increase-decrease trend in the cultivated land and unused land. While it was an inverted V-shape in the water land and a gradually decline in the construction land. The coupling impact between land use types and age factors on watershed lagged effect is particularly significant $(P<0.001)$. (3)The impact difference of land use type transfer on watershed lagged effect is not significant $(P>0.05)$ between different lagged periods $\left(X_{t-0}-X_{t-3}\right)$. However, the impact on lagged intensity gradually increases for wood land transfer with the prolongation of lagged periods, and reaches the maximum for the construction land transfer in the lag-1 period $\left(X_{t-1}\right)$, and changes little for other types. The $R$ absolute value of the influences on lagged frequency is shown an inverted $V$-shape for the transfer of grass land and wood land, that is, the maximum in the lag-1 period $\left(X_{t-1}\right)$ and lag-2 period $\left(X_{t-2}\right)$, respectively. There is a $V$-shape for the transfer of water land and cultivated land, and reaches the minimum values in the lag-1 period $\left(X_{t-1}\right)$ and lag-2 period $\left(X_{t-2}\right)$, and shows an increase-decrease-increase trend for that of the unused land. 
To eliminate the correlation between different indicators of morphological characteristics for land use types and reduce the number of variables, the 48 indices of morphological characteristics were made the principal component analysis in this paper, and were extracted the principal components with the eigenvalue greater than 1.Therefore it extracted the six principal components $\left(Z_{l}-Z_{6}\right)$ of the cultivated land and grass land, five principal components $\left(Z_{l}-Z_{5}\right)$ of the wood land, five and six principal components $\left(Z_{1}-Z_{5}, Z_{6}\right)$ of the water land, and four principal components $\left(Z_{l}-Z_{4}\right)$ of the construction land. However, it is relatively small for area percentage of unused land, and is not significant for the morphological characteristics. Thus the principal component analysis was not carried out (Figs. 8-10).

(1) In general, the $Z s$ of land use types all have some the influences on watershed lagged effect in different lagged intensity is overall shown a negative-positive-negative phenomenon for the morphological characteristics of wood land, grass land and construction land, a negative-positive alternating phenomenon for the cultivated land $\left(Z_{l^{-}} Z_{6}\right)$ and water land $\left(Z_{1}-Z_{5}\right)$.There is just the opposite of the impacts on lagged frequency (Fig.8). The impact on lagged intensity was observed a negative-positive alternating phenomenon for the $Z_{l}-Z_{6}$ of cultivated land in the 1970s-2010s, a negative-positive-negative phenomenon for the $Z_{1}-Z_{4}$ of construction land, and more complex for other types. However, it was just the opposite for the influence on lagged frequency (Fig.9). The impact of the Zs on lagged intensity is appeared a negative-positive alternating phenomenon for cultivated land $\left(Z_{l}-Z_{6}\right)$ and water land $\left(Z_{l}-Z_{5}\right)$ in different time scales (1-12 months), a negative-positive-negative phenomenon for wood land, grass land and construction land. However, it is just the opposite of influences on lagged frequency (Fig.10). (2)The impact difference of different $Z s$ on lagged effect is particularly significant $(P<0.001)$ for the morphological characteristics of single land use type in different lagged periods $\left(X_{t-0}-X_{t-3}\right)$, different ages (1970s-2010s) and different time scales (1-12 months). Among them, 
the $F$ value of the largest impact on lagged intensity/frequency is found in the grass land in the $X_{t-0-} X_{t-3}$, followed by the water land and wood land, and the smallest in the cultivated land and construction land. And that of the impact on lagged intensity/frequency is more larger in construction land than in cultivated land and woodland in the 1970s-2010s, and the smallest in the water land and grass land (Fig.9). The $F$ value of the impacts on the lagged intensity/frequency is the grass land>water land and cultivated land>wood land and construction land in the 1-12 month scales (Fig.10). Meanwhile, the influence differences of the $Z s$ on lagged intensity/frequency are also significant $(P<0.001)$ in the $X_{t-0}-X_{t-3}, 1970 \mathrm{~s}-2010 \mathrm{~s}$ and 1-12 month scales, respectively (Figs.8,9,10). (3) For the $Z s$ of morphological characteristics of single land use type in the $X_{t-0}-X_{t-3}$, the $R$ absolute value of the impacts on lagged intensity is the grass land and water land (lag-2 period) >cultivated land (lag-2 period) and wood land (lag-1 period) >construction land (lag-2 period). The $R$ absolute value of the impacts on lagged frequency gradually increases for the $Z s$ of grass land, water land, wood land and construction land with the prolongation of lagged periods, and reaches the maximum in the lag-3 period $\left(X_{t-3}\right)$.And it is the largest for the cultivated land in the lag-2 period $\left(X_{t-2}\right)$ (Fig.8). The $R$ absolute value of the $Z s$ impacts on the lagged intensity was the largest for the grass land in the 1970s-2010s, and gradually decreased for the cultivated land, water land and wood land with the increase of years (ages). And that of the Zs impacts on the lagged frequency was the largest for the cultivated land and grass land with the maximum in the 1980s,and gradually declined for the wood land and water land with the increase of years (ages),and varied little for the construction land (Fig.9). The $R$ absolute value of the influences on lagged intensity is to increase for the $Z s$ of land use types in the 1-12 month scales. Among them, it is the largest for the grass land and water land, and reaches the maximum in the 9-month scale, followed by the wood land (the maximum in the 9-month scale) and cultivated land (the maximum in the 6-month scale),and the smallest for the construction land (the maximum in the 9-month scale). And with the increase of time scales, that of the influences on lagged frequency is to increase for the cultivated land, wood land and construction land, and to decline for the grass 


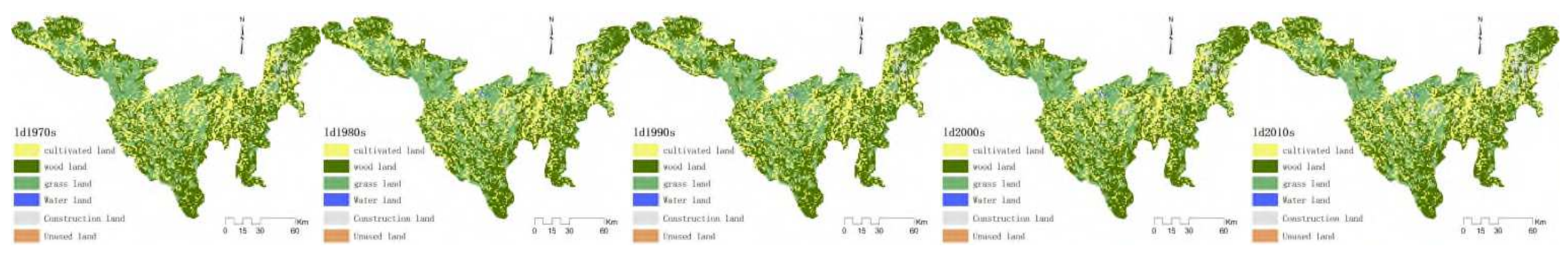

(a) In the 1970s

(b) In the $1980 \mathrm{~s}$

(c) In the 1990s

(d) In the $2000 \mathrm{~s}$

(e) In the 2010s

Fig. 2 Spatial distribution pattern of land use types in the 1970s-2010s

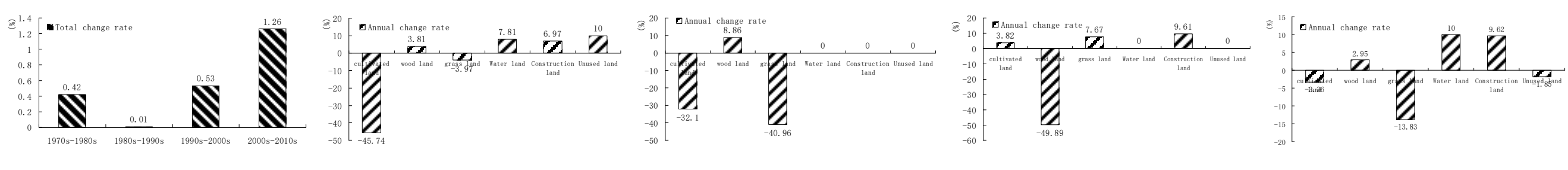
(a) The overall changing rate of land use types
(b) In the $1970 \mathrm{~s}-1980 \mathrm{~s}$
(c) In the $1980 \mathrm{~s}-1990 \mathrm{~s}$
(d) In the 1990s-2000s
(e) In the 2000s-2010s

Fig. 3 The changing rate of land use types in the different ages

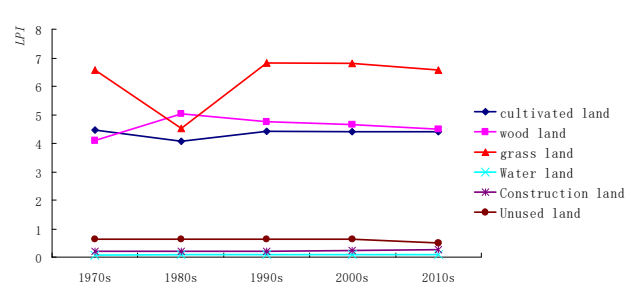

(a) The $L P I$ index

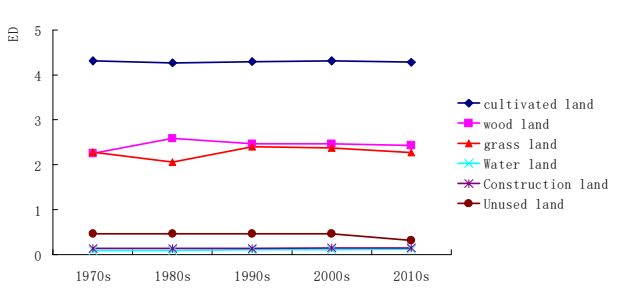

(b) The $E D$ index

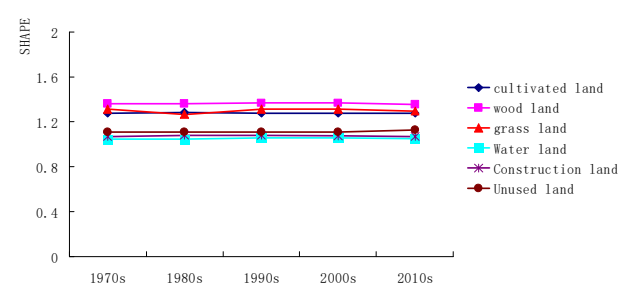

(c) The SHAPE index

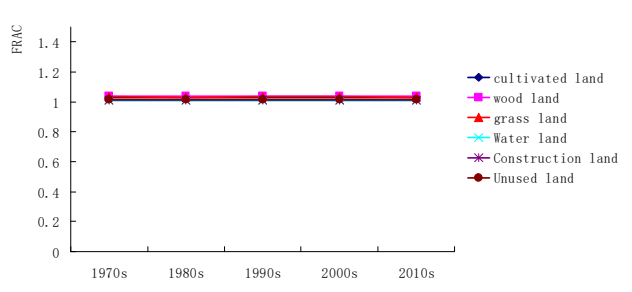

(d) The FRAC index

Fig.4 The morphological characteristic of land use types in the 1970s-2010s 


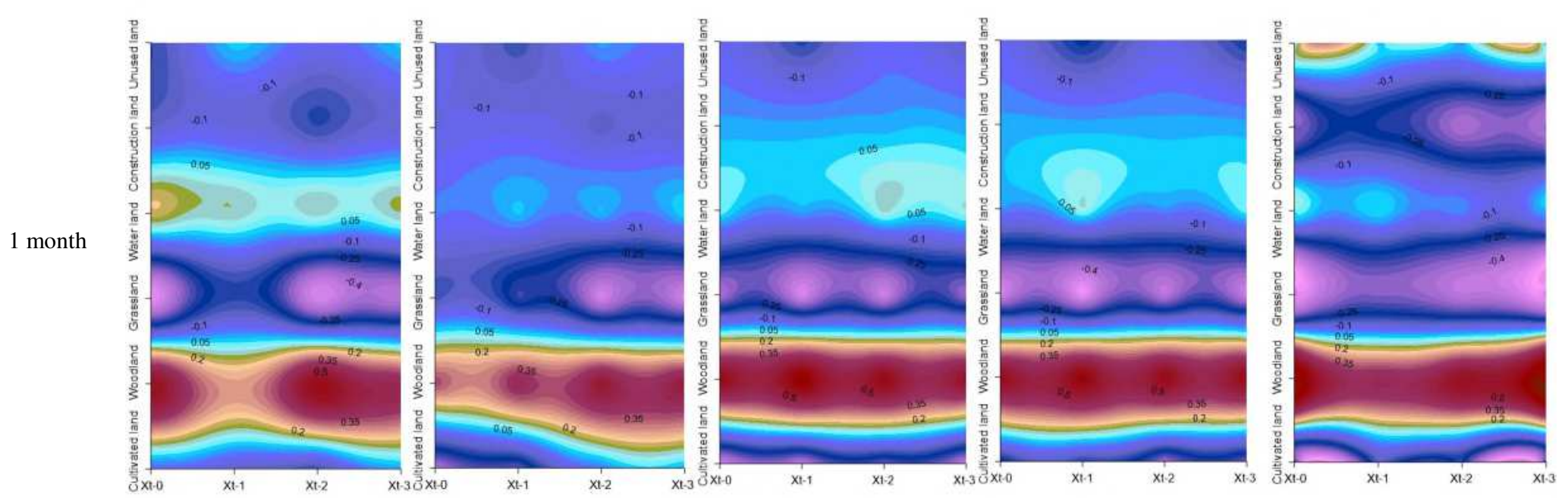



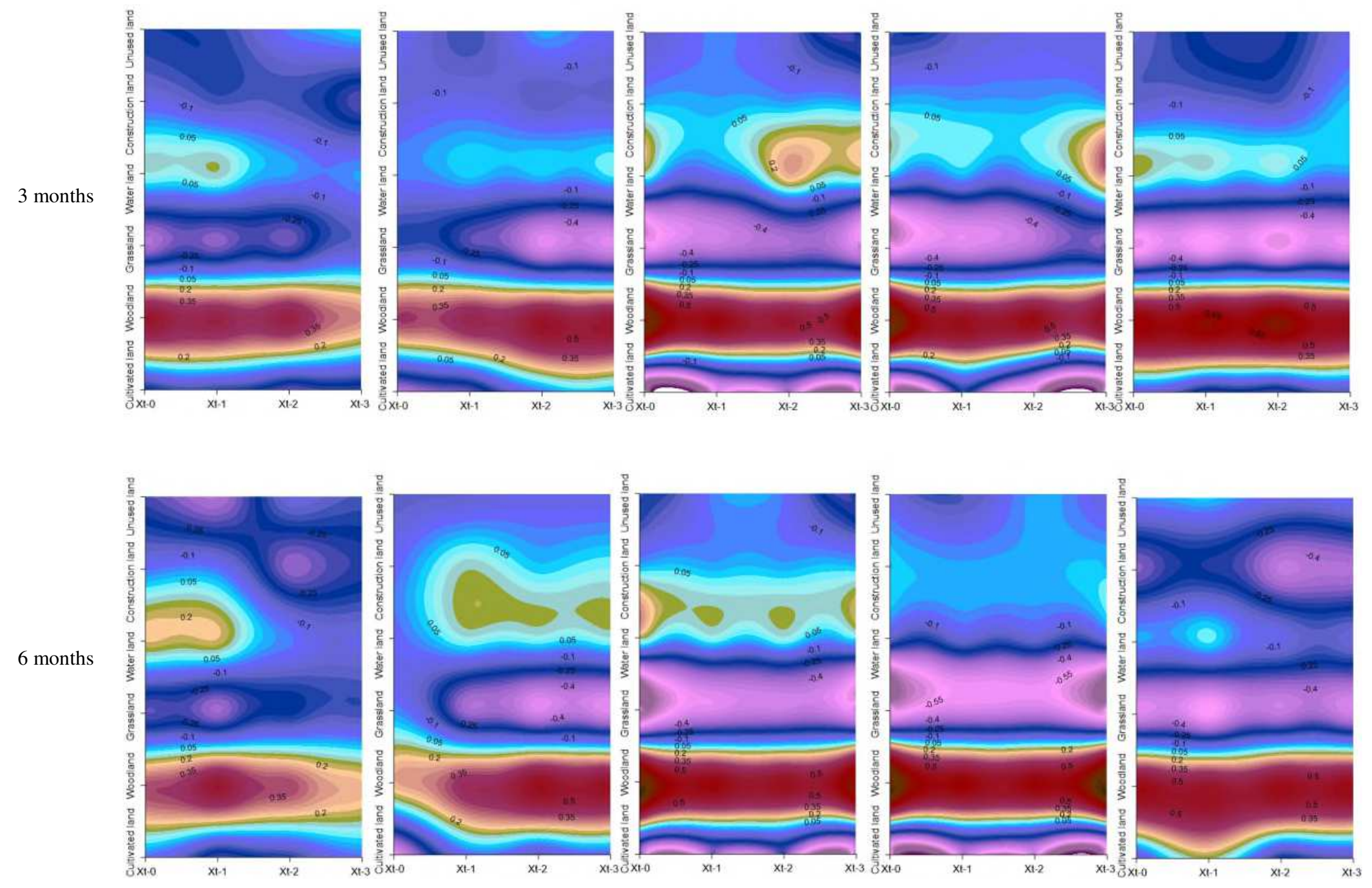

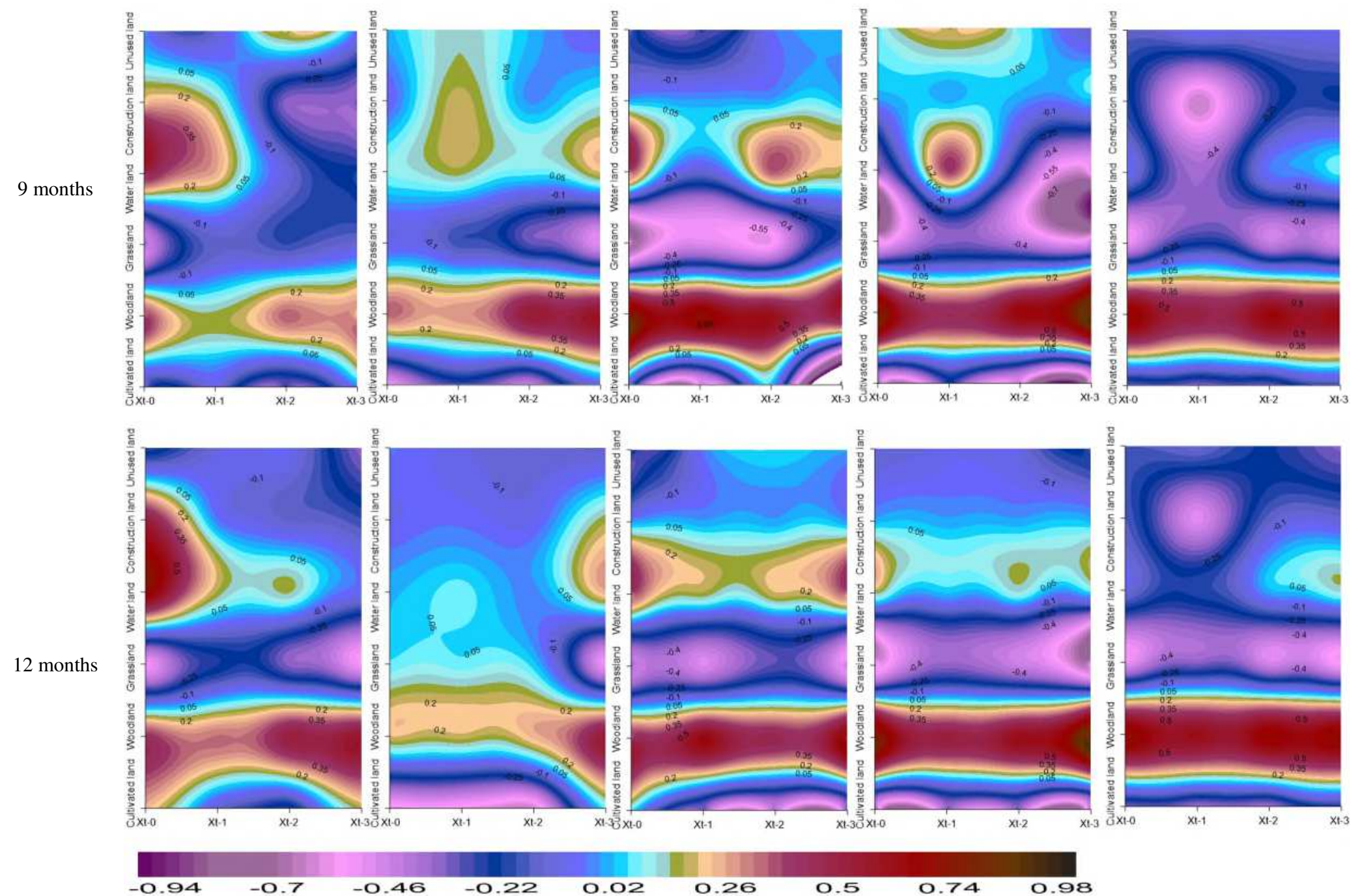

Fig.5 The relationship between land use types and watershed lagged intensities 

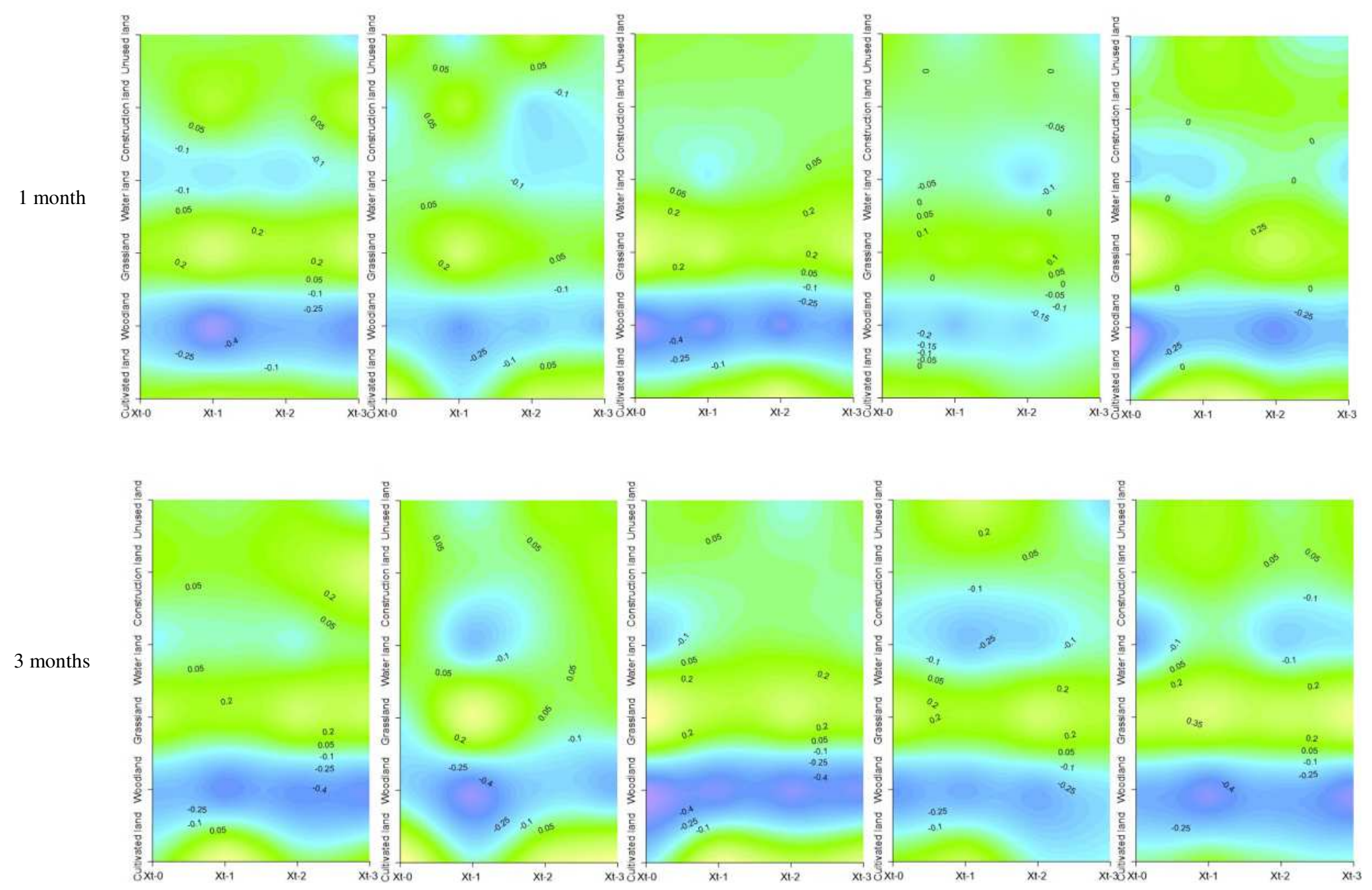

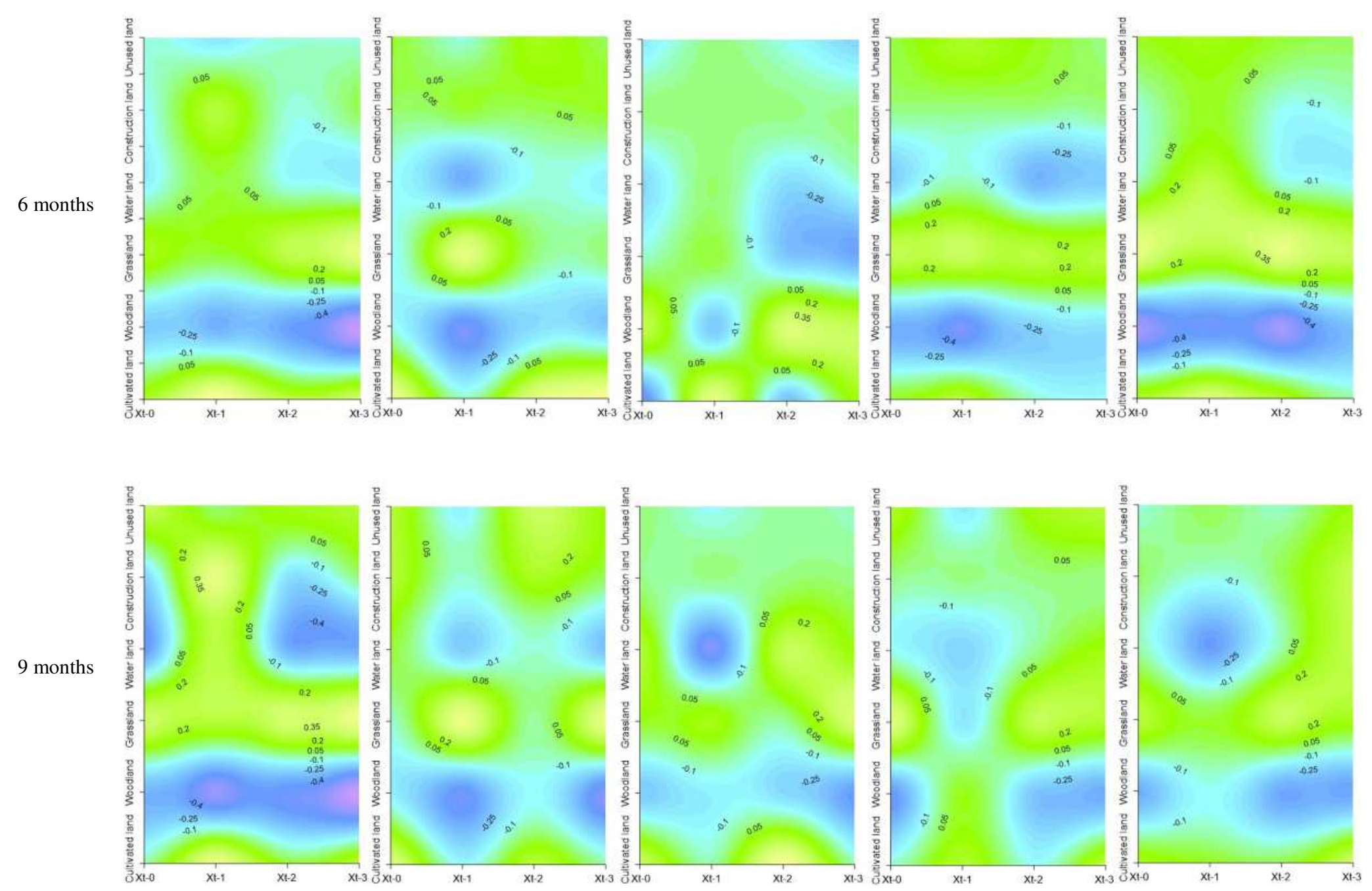


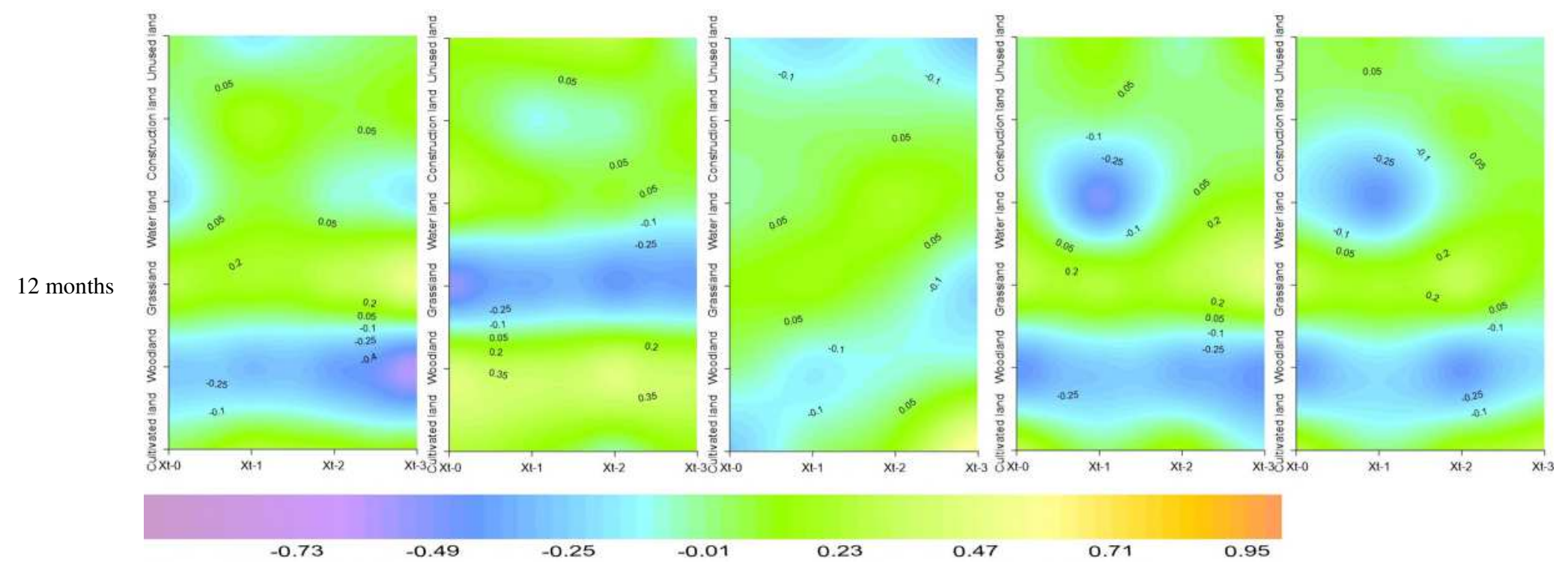

Fig.6 The relationship between land use types and watershed lagged frequencies 

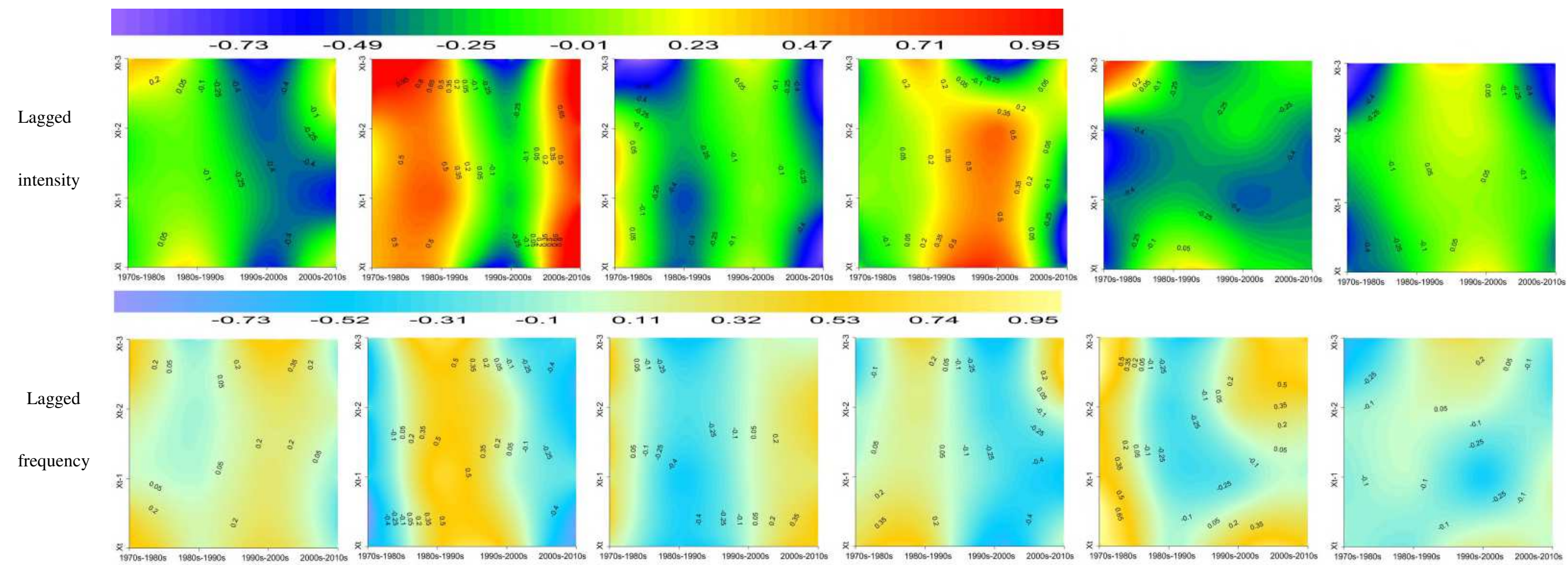

Fig.7 The relationship between land type transfer and watershed lagged effect in the 1970s-2010s 


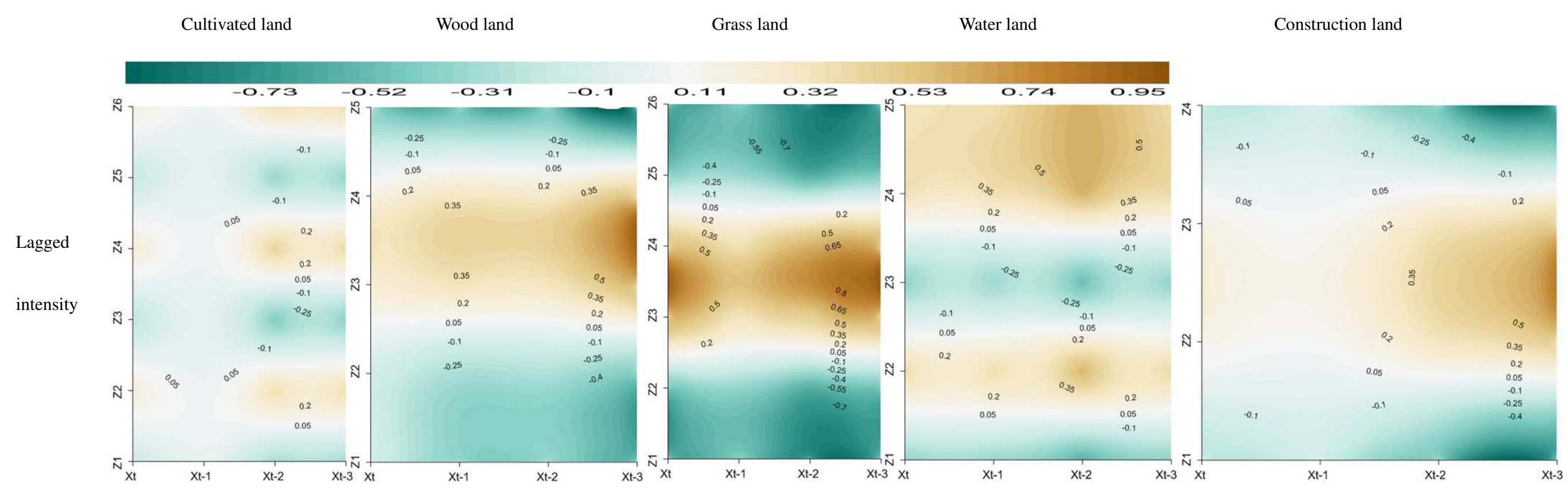




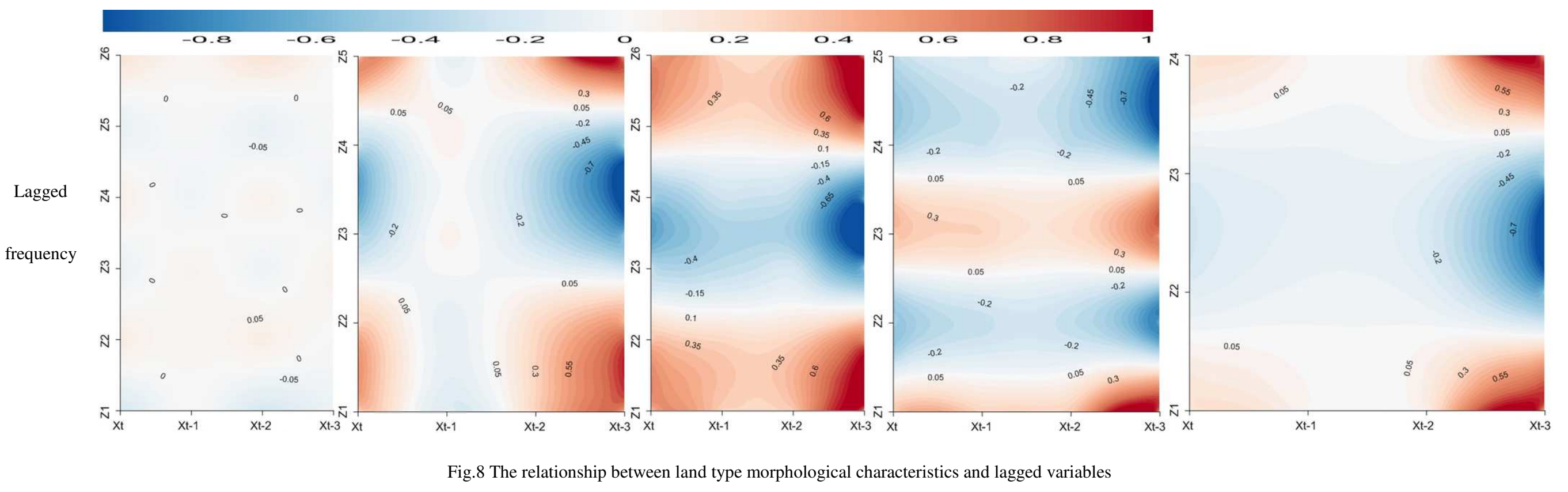

Cultivated land

Wood land

Grass land

Water land

Construction land 

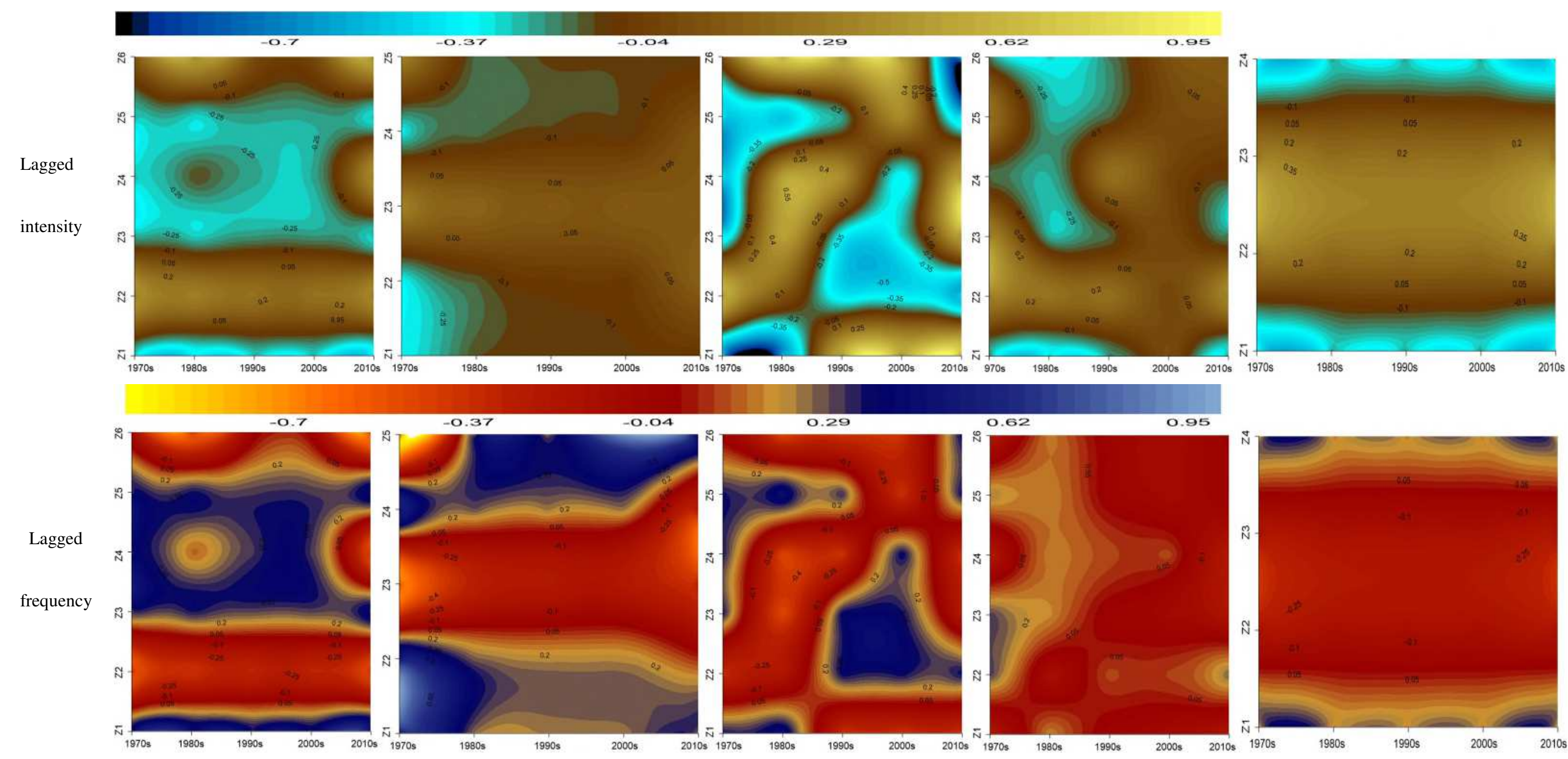

Fig.9 The relationship between land type morphological characteristics and ages 


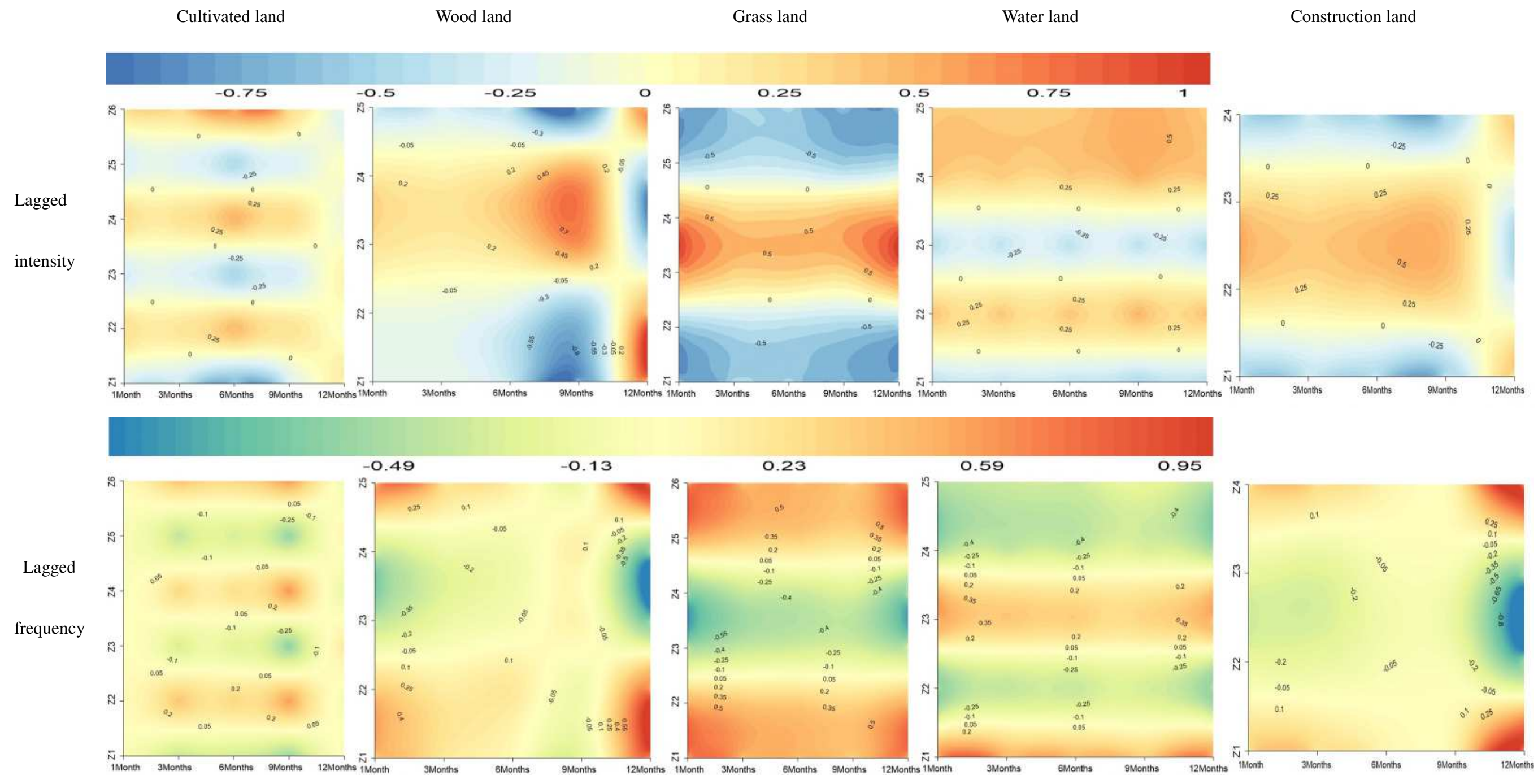


Fig.10 The relationship between land type morphological characteristics and time scales 


\section{Discussion}

It is well known that the streamflow is an integrated response to basin inputs (climate), water transfer, water

losses by evapotranspiration storage processes, and the effects of human activities on natural water flows

(López-Moreno et al., 2013;Vicente-Serrano et al., 2005; McGuire et al.,2006). Prior to reaching the stream

network a large proportion of precipitation is stored in various hydrological subsystems (including snowpack, soil

moisture, groundwater reserves, reservoir storages) depended on the basin medium types (geology, topography,

soils and vegetation) and their spatial coupling structures(Post et al., 1996; Soulsby et al., 2006; Lorenzo-Lacruz

et al., 2010; McDonnell et al., 2010; Fleig et al., 2011). There are the double aquifer media on the surface and

underground, and double water system structures on the surface and underground in Karst drainage basins compared

with the normal basins, which is very significant response to the atmospheric precipitation (Wang et al., 2002; He et al.,

(2015). Especially different sizes of water-stored spaces, such as the solution gap, solution hole and pipeline, as

well as the underground cave and underground corridor, are formed in the Karst drainage basins under the

differential erosion or solution effect of soluble water, which will make the basins have a certain water storage

capacity. Therefore, the response of runoff to rainfall shows a certain lag. There are the different aquifer media and spatial coupling structures in the different basins, which will cause the watershed water-stored capacity. The previous studies have shown that drought propagation is different in an semi-arid climate and a climate with snow accumulation in winter, and it differs between mountainous catchments, catchments with many lakes and wetlands, and catchments with mild slopes and large, porous aquifers (Van Loon 2013). For example, the propagation time is 1 month from the meteorological to hydrological drought, 2 months from the hydrological to agricultural drought, and 2-3 months from hydrological to vegetation drought (Li et al., 2020b). 
effect result of human activities on the watershed media. The spatial pattern of land use types is determined by the type,

341 quantity, shape, spatial distribution and combination of land use/land cover, and the patch is the basic component unit of spatial pattern of land use/land cover (Liu, et al.,20012 \& 2002). The patches of different land use types, such as the cultivated land, woodland, grassland, construction land, etc., show the different graphic characteristics due to different formation mechanisms, and the graphic characteristics are mainly shown the shape and spatial distribution of land use/land cover patches. Human activities eventually lead to the changes of land use types, quantity and morphological characteristics. This study prove that the land use and change all have an impacts on the watershed lagged effect, and show the positive and negative differences. Human activities not only lead to the increasing or decreasing of land use types, and the interconversion between the different land types, but also lead to the complexity of the boundary distribution of land types, which will affect the integrity of watershed water-stored spaces, and further influence the watershed lagged effect characteristics. Landscape index is the most effective quantitative index of the land types' morphological characteristics. For example, the larger the patch density index is, the more concentrated and fragmented the land type distribution is, on the contrary, the more scattered and continuous. The larger the largest patch index is, the smaller the intensity and frequency of human activities are, which shows that the more concentrated the land type distribution is, and the simpler the boundary condition is. Conversely, the larger the intensity of human activities, the higher the frequency. It means that the more scattered the land type distribution is, and the more complex the boundary condition is. The smaller the patch shape index is, the more complex the morphological characteristic of land types is, on the contrary, the simpler it is. The larger the patch fractal dimension index is, the more complex the land use types is, and the more circuitous the boundary distribution is. On the contrary, the simpler the land use type distribution is, the more regular the boundary is (Li et al., 2019; Song et al.,2017). This study demonstrates that the principal component factors $\left(Z_{1}-Z_{4}, Z_{5}, Z_{6}\right)$ of 48 indicators of land type morphological characteristics all have influences on the lagged intensity/frequency, and it shows the positive and negative differences in the different lagged periods $\left(X_{t-0}-X_{t-3}\right)$, different ages (1970s-2010s) and different time scales (1-12 months). Indicating that human activities not only affect the spatial 
pattern of land use types, but also affect the morphological distribution characteristics, which will influence the watershed lagged effect. Meanwhile, the $Z s$ of different morphological characteristics of the same land use type or different land use types all have particularly significant impacts $(P<0.001)$ on the lagged intensity/frequency with the prolongations of lagged periods $\left(X_{t-0}-X_{t-3}\right)$, the change of ages (1970s-2010s) and the increasing of time scales (1-12 months).

In summary, the watershed medium is an important component in Karst drainage basins, where there are some water-stored spaces formed under the differential erosion or dissolution effects of soluble water. It will provide the spaces and places for the atmospheric precipitation lagged flow on the surface and underground, promote the basins showing the lagged effect characteristics. Land use/land cover is the effect manner of human activities on the watershed media, and the spatial pattern of land use/land cover is the effect results of human activities on the watershed media, which will promote or inhibit the characteristics of watershed lagged effects.

\section{Conclusion}

(1) The land use/land cover all have the significant impact on the watershed lagged effects, and show a positive and negative difference. Among them, the impact of the wood land and water land on lagged intensity is positive, others are negative, and the impact on the lagged frequency is just the opposite. The impact differences of land use types on watershed lagged effects are particularly significant $(P<0.001)$ with the changing of ages, the prolongation of lagged periods, as well as the increasing of time scales.

(2) The $R$ absolute values of the $Z s$ impacts on the lagged intensities were shown an increase-decrease-increase trend with the changing of ages (1970s-2010s) in the wood land and grass land, and shown just the opposite in the construction land region. And that of the $Z s$ impacts on the lagged intensities was shown an inverted $V$-shape in the water land, and reached the maximum in the 1990s-2000s, and changed less in the construction land and unused land.

The $R$ absolute values of the $Z s$ impacts on the lagged frequencies reached the maximum in the grass land and wood land in the lag-1 period $\left(X_{t-1}\right)$ and lag-2 period $\left(X_{t-2}\right)$ with the prolongation of lagged periods, and the minimum in the 
cultivated land and water land in the lag-1 period $\left(X_{t-1}\right)$ and lag-2 period $\left(X_{t-2}\right)$, respectively.

(3) The principal component factors $(Z s)$ of morphological characteristics of land use types all have the impacts on the lagged effects with the particularly significant differences in the different lagged periods $\left(X_{t-0}-X_{t-3}\right)$, different ages (1970s-2010s) and different time scales (1-12 months). Among them, the $F$ statistic values of the $Z s$ impacts on the lagged intensity/frequency are the largest in the grass land in the $X_{t-0}-X_{t-3}$, followed by the water land and wood land, the smallest in the cultivated land and construction land. The impacts of the $Z s$ on the lagged intensity were the largest for the grassland, cultivated land and water land in the 1970s-2010s, and reached the maximum in the 1980s. And that of the $Z s$ gradually decreased for the wood land with the increasing of ages, and changed less in the construction land. The $R$ absolute values of the $Z s$ impacts on the lagged intensities are the largest for the grass land and water land in the 1-12 month scales, and increase with the increasing of time scales (the maximum value in the 9-month scale), followed by the wood land and cultivated land with the maximum in the 6- and 9- month scales, And that of the Zs impacts on the lagged intensities is the smallest for the construction land, and gradually increases with the increasing of time scales (the maximum in the 9-month scale).

\section{Acknowledgements}

This study was supported by the Natural Science Foundation of China (u1612441,41471032); Project for National Top Discipline Construction of Guizhou Province (85 2017 Qianjiao Keyan Fa); 2015 Doctor Scientific Research Startup Project of Guizhou Normal University.

\section{References}

He Z., Liang H., Yang Z.,etc.,2018a. Temporal-spatial evolution of the hydrologic drought characteristics of the karst drainage basins in South China. Int J Appl Earth Obs Geoinformation,64:22-30. http://dx.doi.org/10.1016/j.jag.2017.08.010.

He Z., Liang H., Yang, Z.,etc.,2018b. Water system characteristics of Karst river basins in South China and their driving mechanisms 
He Z., Chen X., Liang H. etc.,2015. Studies on the mechanism of watershed hydrologic droughts based on the combined structure of typical Karst lithology:Taking Guizhou Province as a case.Chinese Journal of Geology,50(1):340-353.

He Z., Chen X., Liang H., 2014. Study on spatial pattern of land-using types and hydrologic droughts for typical karst basin of

He Z., Chen, X., Liang, H., 2013a. The hydrological drought analysis of the karst basin based on the soil systematic structure-taking guizhou province as a case. J. Nat.Resour. 28 (10), 1731-1741. http://dx.doi.org/10.11849/zrzyxb.2013.10.008.

He Z., Chen X., Liang H., 2013b. The Hydrological Drought Simulating in Karst Basin Based on Coupled Soil Factors—— Taking by using cross wavelet analysis and spatial autocorrelation. Agricultural and Forest Meteorology,280:1-9. https://doi.org/10.1016/j.agrformet.2019.107809.

Li Q., He P., He Y., 2020b. Investigation to the relation between meteorological drought and hydrological drought in the upper

Li W., Tian C., Ma X. 2019. Mechanisms and spatial pattern of land use changes of the urban tourism complex: A case study of study in the Ebro basin. Journal of Hydrology, 477, 175-188. http://dx.doi.org/10.1016/j.jhydrol.2012.11.028. 
Liang H.,Wang J., 1998. Arelative analysis between the lithological features and the characteristics of flood discharge and low flow in Karst district—Case study of the rivers, Guizhou Province, Carsologica Sinica,17(1):67-73.

Liang H.,1997.Preliminary Study on the Characteristics of Flood Discharge and Low Flow Influenced by the Scale of Karst Drainage Basin. Carsologica Sinica,16(2):121-129.

Liang H.,Yang M.,1995. Flow Gathering Analysis of Hydrologeomorphologic System in Karst Drainage Basin.Carsologica Sinica, 14(2):186-193.

McGuire K., McDonnell J., 2006. A review and evaluation of catchment transit time modeling. Journal of Hydrology. 330:543-563. https://doi.org/10.1016/j.jhydrol.2006.04.020.

Niu J.,Chen J.,Sun L.,2018. Time-lag effects of vegetation responses to soil moisture evolution: a case study in the Xijiang basin in South China. Stoch Environ Res Risk Assess,32:2423-2432. https://doi.org/10.1007/s00477-017-1492-y.

Nicholson S., Farrar T.1994. The inflfluence of soil type on the relationships between NDVI, rainfall, and soil moisture in semaird Botswana: I. NDVI response to rainfall. Remote Sensing of Environment,50:107-120.

Song G., Wang P.,2017.Spatial Pattern of Land Use Along the Terrain Gradient of County in Songnen High Plain: A Case Study of Bayan County. Scientia Geograhpica Sinica,37(8):1218-1225. https://doi.org/10.13249/j.cnki.sgs.2017.08.012.

Van Loon, A.F., 2013. On the propagation of drought. How climate and catchment characteristics influence hydrological drought development and recovery. Ph.D. thesis, Wageningen University. <http://edepot.wur.nl/249786> (last accessed 28.05.13).

Vicente-Serrano S., López-Moreno J., 2005. Hydrological response to different time scales of climatological drought: an evaluation of the standardized precipitation index.Hydrology and Earth System Sciences. 9, 523-533. https://hal.archives-ouvertes.fr/hal-00304863.

Wang Z., Liang H.,Yang M.,2002. Analysis of the impact of different landform types on low flow modulus in karst regions:a case study of rivers in Guizhou Province. CARSOLOGICA SINICA,21(4):441-448.http://dx.doi.org/10.3321/j.issn:1000-0585.2002.04.006. 
455 China. Arabian Journal of Geosciences,364:1-13. https://doi.org/10.1007/s12517-019-4524-8.

456 Zhou J., Li Q., Wang L. etc.,2019.Impact of Climate Change and Land-Use on the Propagation from Meteorological Drought to

457 Hydrological Drought in the Eastern Qilian Mountains.Water,1062:1-19.https://doi.org/10.3390/w11081602. 